\title{
Model-Based Current Sharing Approach for DCM Interleaved Flyback Micro-Inverter
}

\author{
Mi Dong ${ }^{1}$, Xiaoyu Tian ${ }^{1}$, $\mathrm{Li} \mathrm{Li}^{1}$, Dongran Song ${ }^{1, *}$, Lina Wang ${ }^{2, *(1)}$ and Miao Zhao ${ }^{3}$ \\ 1 School of Information Science and Engineering, Yuelu Road, Central South University, Changsha 410083, \\ China; mi.dong@csu.edu.cn (D.M.); txy15388967580@163.com (X.T.); lili112209@163.com (L.L.) \\ 2 School of Automation Science and Electrical Engineering, Xueyuan Road, Beihang University, \\ Beijing 100191, China \\ 3 State Grid Hunan Electric Power Company Limited Research Institute, Changsha 410007, China; \\ terrence3333@163.com \\ * Correspondence: humble_szy@163.com (D.S.); wangln@buaa.edu.cn (L.W.); \\ Tel.: +86-181-6365-6151 (D.S.); +86-135-2277-3516 (L.W.)
}

Received: 1 June 2018; Accepted: 21 June 2018; Published: 27 June 2018

\begin{abstract}
Current sharing control is a challenge for a discontinuous conduction mode (DCM) micro-inverter based on interleaved flyback topology. To solve this problem, this study proposes a novel and systemic model-based approach. Firstly, an accurate fourth-order model is presented for the interleaved flyback circuit, which takes the two flybacks' parameter mismatch and coupling into account. Secondly, based on the presented model, a continuous time sliding mode current controller is proposed to tackle the output imbalance caused by parameter mismatch, coupling and disturbance. The proposed controller is derived from the Lyapunov function without switching conditions. Finally, the effectiveness of the proposed model and control method is validated by simulation tests using MATLAB/SIMULINK. Simulation results show that the proposed approach improves the current sharing for the interleaved flyback micro-inverter when compared to the conventional current sharing approach.
\end{abstract}

Keywords: accurate modeling; sliding mode control (SMC); current control; interleaved flyback

\section{Introduction}

In recent years, power generation technology has been a popular research topic in the photovoltaic (PV) and wind energy field [1-3]. The typical PV generation module, which is called the micro-inverter, makes it possible to realize the individual maximum power point tracking (MPPT) of each PV panel. While a large number of studies have been done on the topology and control strategy for the micro-inverters [4-6], the flyback topology has attracted significant interest due to its simple structure, low cost and high reliability. It not only enables individual operation of each module, but also reduces the power loss caused by the mismatch between modules [7-9]. Furthermore, the parallel and interleaved structure of the flyback can reduce the system loss, decrease current ripple, prevent the single point failure, and offer 'plug and play' feature to the system [10-13].

Flyback converters operating in discontinuous conduction mode (DCM) are widely used because their output current is easy to control [14]. Despite much research [14-16] having been conducted on the DCM converter with regard to conversion efficiency enhancement, harmonic reduction and compensation of output current phase-leg, the current sharing between dual-flyback converters has been ignored under the assumption that the design parameters of the two flyback converters are the same. However, such an assumption is not generally true in the industrial field, as the precise parameters may not be guaranteed under a cost-effective manufacturing procedure. Additionally, 
the two converters would not be operating under the exact same conditions in practice due to parameter variations caused by device ageing and other uncertainties. Together with the coupling between the two flyback converters, the parameter mismatch could cause the output current imbalance, which potentially overloads one of the converters. Consequently, the efficiency and reliability of the micro-converter system drops. In the worst case, the output current imbalance may cause the overloaded converter to suffer from thermal runaway $[17,18]$. Although there has been a great deal of research into dynamic performances such as conversion efficiency and output current ripple, current sharing has not been completely studied. To address the output imbalance issue, current sharing control strategies for the dual-flyback converters should be studied, the aim of which would be to build up an accurate model describing the dynamic characteristic of the converters and their couplings.

When converters such as buck, boost and flyback operate in DCM, there are two modeling methods, namely, the average small-signal [16,19-21] and the duty-ratio constraint method [22-28]. The average small-signal modeling method has mainly been employed to study system conversion efficiency $[16,20]$ and harmonic distortion $[19,21]$. The average small-signal modeling method is over-simplified through ignoring the equivalent series resistances of the inductances in primary/secondary side of transformer, which could result in large differences and discrepancies at high frequencies due to the high-frequency pole. The duty-radio constraint method is a modified average-state-space method, in which the parasitic parameters of the converter can be taken into consideration. Consequently, the resulting models have good dynamic performance at low frequency and at high frequency [22]. Accordingly, the models based on the duty-ratio constraint method have been widely employed in application fields that call for high accuracy models, such as studying the relationship of the transfer function of the duty-cycle to the weighted-output-voltage of single-input multiple-output flyback converters [23], analyzing the influence of parasitic parameters on input current distortion with a boost power factor correction converter [24], and discussing power flow between two inputs of an interleaved-boost full-bridge three-port converter [25]. Considering that current sharing requires a precise model of flyback micro-inverter, the duty-ratio constraint method is a good candidate for modeling, but the modeling issue has not been covered in the existing literature.

The available methods of achieving current sharing can be categorized into two types, hardware-added type [29-31] and hardware-free type. The first type requires additional hardware, such as equivalent resonant capacitor and series bus capacitors, which would increase the system cost directly. The second type uses a current sharing control method, which includes the droop control method [32-34], distributed control method [35] and PI control [17,18]. The droop control and distributed control have been applied to power supply modules. The droop control method noted for being simple, inexpensive and efficient, since there is no communication connection among power supply modules [33]. The distributed control method uses the consensus algorithm, in which information such as current and voltage of the distributed modules is required [35]. The current sharing is achieved through feedback of output signals to the control duty cycle, which could cause a control delay compared to the method of controlling the primary side current directly [19]. Meanwhile, these methods are inapplicable to the dual flyback converters when the duty cycles of two flyback converters are unfixed. For the CCM interleaved flyback micro-inverter, the multiple PI controllers are developed in $[17,18]$ to achieve the current sharing, but they could not track the sinusoidal reference current without static error [36] and may increase the total harmonic distortions (THDs) of system. Besides, there are several parameters require to design for PI controllers, which increase the design complexity. Therefore, the current sharing control for DCM flyback micro-inverter needs to be studied.

To solve the aforementioned issue, a model-based current sharing approach for the DCM Interleaved Flyback micro-inverter is proposed in this paper. On one hand, the accurate and novel full-fourth-order model is established in the DCM interleaved flyback micro-inverter, showing the imbalance of the system parameters and coupling of the two flyback converters. On the other hand, to solve the load imbalance caused by parameter imbalance and disturbance, a current controller 
based on sliding mode control (SMC) for dual-flyback converter is designed, which ensures equal sharing of the injected current, and improves the dynamic performance of the system. In the proposed SMC, the primary currents of the presented model are used as controlled variables to achieve current sharing. This ensures equal sharing of the injected current and improves the dynamic performance of the system. The remaining sections are organized as follows: the accurate fourth-order model operating in DCM is introduced and analyzed in Section 2. The SMC controller is designed in Section 3, and Section 4 presents the simulations in MATLAB/SIMULINK. Finally, Section 5 concludes the study.

\section{Working Principle and Dynamic Modeling}

\subsection{Working Principle}

The DCM interleaved flyback has been widely used in AC-PV modules, because its output current is easy to control and it can achieve high efficiency [16]. Figure 1 illustrates the circuit of the interleaved flyback micro-inverter, which is comprised of a PV module, an input capacitor $C_{p v}$, the Flyback 1 converter, the Flyback 2 converter, an unfolding H-bridge inverter $\left(\mathrm{M}_{1}, \mathrm{M}_{2}, \mathrm{M}_{3}, \mathrm{M}_{4}\right)$ and an output $\mathrm{CL}$ filter. $V_{p v}$ is the PV voltage. $n$ is the transformer turns ratio. $L_{m 1}, L_{m 2}$ are the primary magnetizing inductances of the transformer, respectively. $i_{m 1}, i_{m 2}$ are the primary currents of the transformer, respectively. $i_{s 1}, i_{s 2}$ are the secondary currents of the transformer, respectively. $L_{f}$ is the filter inductor. $C_{f}$ is the filter capacitor. $R_{p 1}, R_{p 2}$ are the equivalent series resistances of the primary magnetizing inductance, respectively. $R_{s 1}, R_{s 2}$ are the equivalent series resistances of the secondary magnetizing inductance, respectively. $R_{f}$ is the equivalent series resistance of the output filter inductor. D is main MOSFET duty cycle.

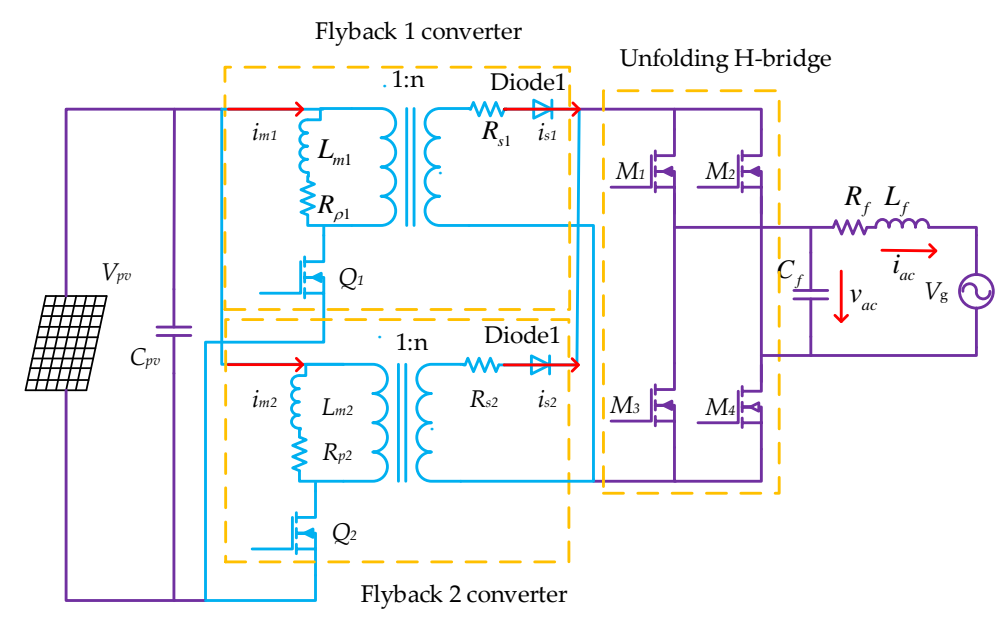

Figure 1. The interleaved flyback mirco-inverter topology.

As shown in Figure 1, the circuit diagram is a double-stage topology. The preceding stage is made up of a PV module and two flyback converters. This stage is controlled to extract maximum power from the PV module and to provide a semi-sinusoidal output current. The post-stage circuit consists of an unfolding H-bridge circuit, which forms a current-unfolding circuit for injecting sinusoidal AC current into the grid. How to control switches $Q_{1}$ and $Q_{2}$ in the preceding stage is studied in this paper.

There are two circumstances $(\mathrm{D}>0.5$ or $\mathrm{D}<0.5)$ for the PWM singles, which are used to control switches $Q_{1}$ and $Q_{2}$ during one switching cycle [14]; the PWM waveforms are shown in detail in Figure 2. Meanwhile, the corresponding equivalent circuits of steady-state operation are illustrated in Figure 3, and Table 1 identifies the operating phases for switches and diodes $\left(\mathrm{Q}_{1}, \mathrm{Q}_{2}\right.$, Diode 1 and Diode 2) with respect to the equivalent circuits. When $\mathrm{D}<0.5$, the primary and secondary current waveforms of the interleaved flyback micro-inverter are shown in Figure $2 b$. The matching current flowing paths in one switching cycle for steady-state path (1) are: Interval $1 \rightarrow$ Interval 2 
$\rightarrow$ Interval $3 \rightarrow$ Interval $4 \rightarrow$ Interval $5 \rightarrow$ Interval 3 . When the next cycle arrives, the secondary inductor currents $i_{s 1}$ and $i_{s 2}$ are reduced to zero, and the steady-state path (2) of matching the current flow is Interval $1 \rightarrow$ Interval $2 \rightarrow$ Interval $3 \rightarrow$ Interval $6 \rightarrow$ Interval $4 \rightarrow$ Interval $5 \rightarrow$ Interval $3 \rightarrow$ Interval 6 . Additionally, when $\mathrm{D}>0.5$, there are six current flowing paths during one switching cycle, and the steady-state operation path is Interval $1 \rightarrow$ Interval $2 \rightarrow$ Interval $7 \rightarrow$ Interval $4 \rightarrow$ Interval $5 \rightarrow$ Interval 7. The model operating in steady-state path (1) is established and explicitly described below.

Table 1. Circuit steady-state operations.

\begin{tabular}{ccccc}
\hline Interval & Switch Q1 & Switch Q2 & Diode 1 & Diode 2 \\
\hline 1 & ON & OFF & OFF & ON \\
2 & ON & OFF & OFF & OFF \\
3 & OFF & OFF & ON & ON \\
4 & OFF & ON & ON & OFF \\
5 & OFF & ON & OFF & OFF \\
6 & OFF & OFF & OFF & OFF \\
7 & ON & ON & OFF & OFF \\
\hline
\end{tabular}

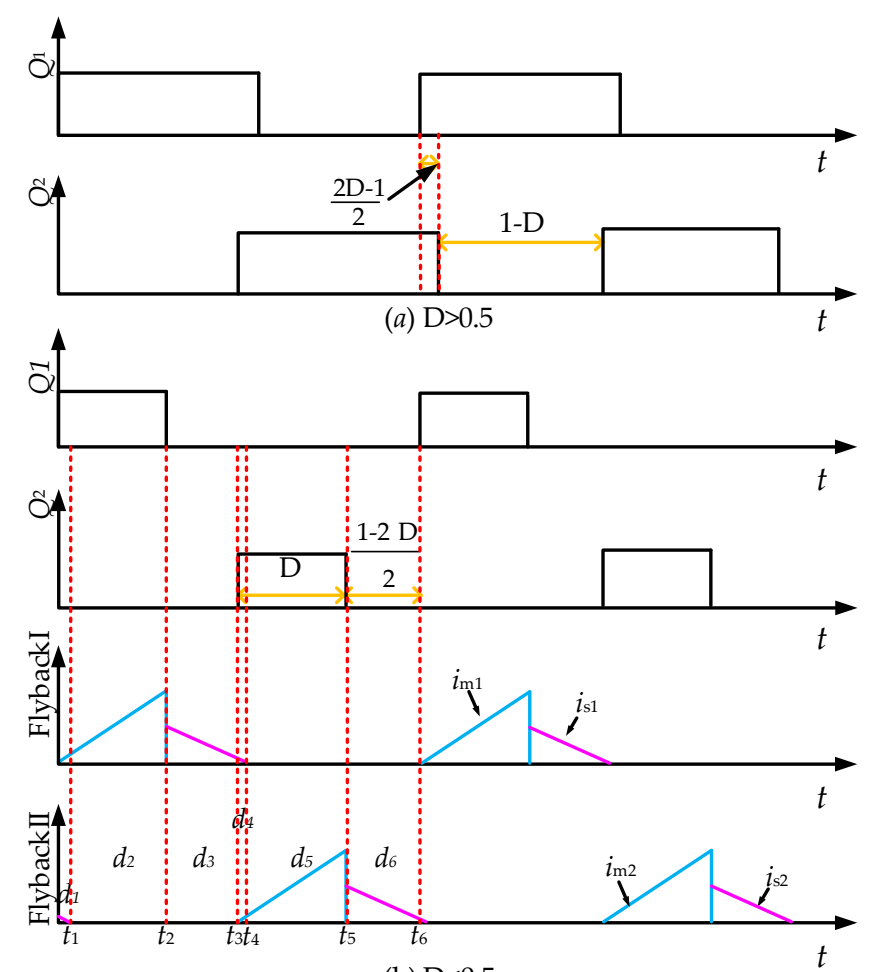

(b) $\mathrm{D}<0.5$

Figure 2. PWM and duty cycle for one switching period and the waveforms of $i_{m 1}, i_{s 1}, i_{m 2}$, and $i_{s 2}$ corresponding to switch Q1, Q2 and Duty cycle state. 


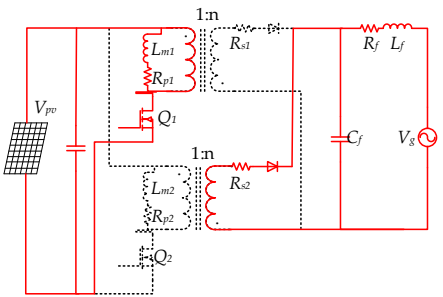

Interval $1 d_{1}:\left[0 \sim \mathrm{t}_{1}\right]$

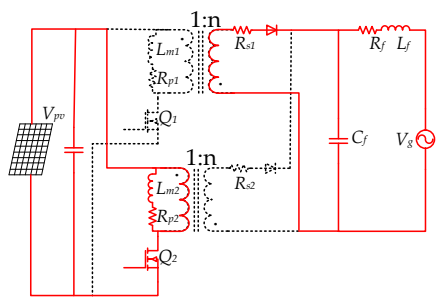

Interval $4 d_{4}:\left[t_{3} \sim t_{4}\right]$

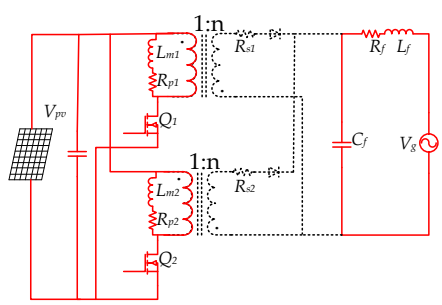

Interval 7

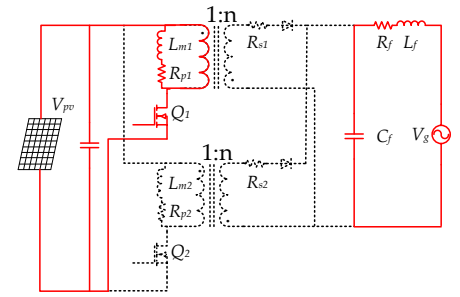

Interval $2 d_{2}:\left[t_{1} \sim t_{2}\right]$

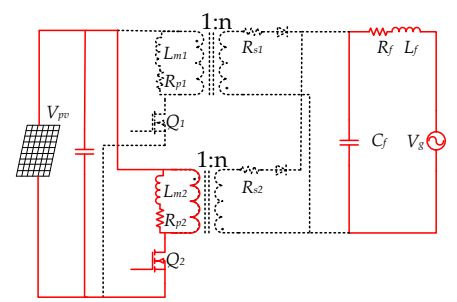

Interval $5 d_{5}:\left[t_{4} \sim t_{5}\right]$

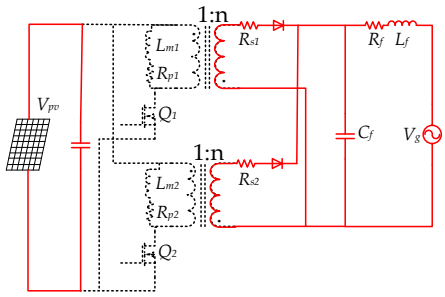

Interval $3 d_{3}:\left[t_{2} \sim t_{3}\right], d_{6}:\left[t_{5} \sim t_{6}\right]$

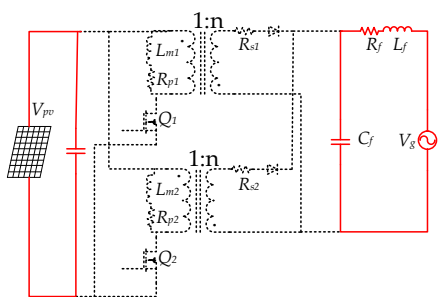

Interval 6

Figure 3. Equivalent circuits for different intervals in steady-state operation.

\subsection{Accurate Dynamic Model in DCM Operation}

In order to facilitate modeling and analysis, the following assumptions are made in this paper:

1. The DC side decoupling capacitor $C_{p v}$ is large enough to neglect the current ripple across the $C_{p v}$;

2. The equivalent series resistances (ESR) of the inductances in primary/secondary side of transformer and the output filter are considered. The transformer leakage inductance is ignored.

As shown in Figure $2 b$, one switching interval is divided into six subintervals. Accurately representing the dynamic of the converter circuit, a precise full-order averaged model $[22,23,25]$ of the converter circuit is used.

$$
\dot{\bar{x}}=\left(\sum_{k=1}^{H}\left(d_{k} \mathrm{~A}_{k}\right)\right) \Phi \bar{x}+\left(\sum_{k=1}^{H}\left(d_{k} \mathrm{~B}_{k}\right)\right)
$$

where $\bar{x}$ represents the average of $x$ in one switching period. $H$ denotes the number of steady-state subintervals in the DCM interleaved flyback $(H=6) . \mathrm{A}_{k}$ and $\mathrm{B}_{k}$ are presented as steady-state equations in k-interval. Equation (1) revises the conventional state-space average equation through matrix $\Phi$, which can accurately predict performance at high frequency (above one-tenth of the switching frequency), particularly in the phase response [22].

$$
\Phi=\operatorname{diag}\left[\begin{array}{llll}
\underbrace{\frac{1}{d_{0 f f_{-} 1}+d_{\text {on_ } 1}}}_{\mathrm{n}_{L}} \frac{1}{d_{0 f f_{-} 2}+d_{o n_{-} 2}} & \cdots & 1
\end{array}\right]
$$

where $d_{\text {off_1 }}=d_{3}+d_{4}, d_{o f f \_}=d_{6}+d_{1}, d_{o n_{-} 1}=d_{1}+d_{2}$ and $d_{o n \_} 2=d_{4}+d_{5} . n_{L}$ denotes the number of inductor currents of the transformer. $d_{o n_{-}}$and $d_{0 n_{-} 2}$ denote duty cycles of switches $\mathrm{Q}_{1}$ and $\mathrm{Q}_{2}$ when 
they are on, respectively. $d_{o f f_{-} 1}$ and $d_{\text {off_2 }}$ represent the time intervals from turn-off of switches $Q_{1}$ and $\mathrm{Q}_{2}$ to the decreasing to zero of the transformer inductor currents, respectively.

From Equations (1) and (2), the state-space averaged large signal model of the interleaved flyback micro-inverter is derived as

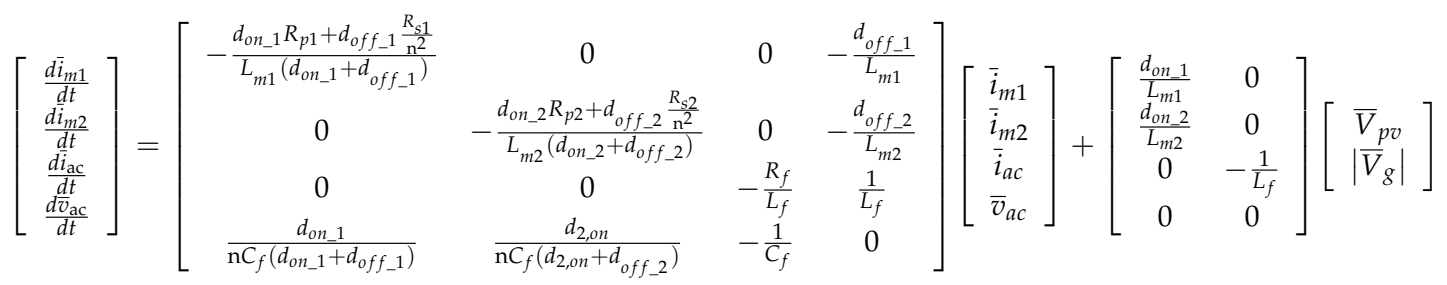

The correlations between $d_{\text {off__ }}(i=1,2)$ and $d_{o n} i(i=1,2)$ are shown as follows

$$
\begin{aligned}
& d_{o f f \_1}=2 L_{m 1} i_{m 1} /\left(d_{o n \_} 1 V_{p v}(t) T_{s}\right)-d_{o n \_1} \\
& d_{o f f \_2}=2 L_{m 2} i_{m 2} /\left(d_{o n \_} 2 V_{p v}(t) T_{s}\right)-d_{o n \_} 2
\end{aligned}
$$

According to Equations (4) and (5), and linearizing Equation (3), the small signal model is derived as follows:

$$
\begin{aligned}
& \dot{\tilde{x}}(t)=A_{D C M} \widetilde{x}+B_{D C M} \widetilde{d}+W_{D C M} Z \\
& y=\left[\begin{array}{llll}
0 & 0 & 1 & 0
\end{array}\right] \widetilde{x}
\end{aligned}
$$

where $\widetilde{x}=\left[\begin{array}{llll}\widetilde{i}_{m 1} & \widetilde{i}_{m 2} & \widetilde{i}_{a c} & \widetilde{v}_{a c}\end{array}\right]^{T}, Z=\left[\begin{array}{cc}\widetilde{V}_{p v} & \widetilde{V}_{g}\end{array}\right]^{T}$, and the parameters $A_{D C M}, B_{D C M}$ and $W_{D C M}$ are derived in Appendix A.

\subsection{Comparisons between the Accurate Dynamic Model and the Existing Model}

To analyze the relationships between dual-flyback converters and output grid current of the accurate dynamic model and existing models, the output current to duty cycle transfer functions of these models are established. The analysis and comparisons between the accurate model and the existing models are shown as follows.

\subsubsection{The Proposed Fourth-Order Model}

Assume the difference between $\widetilde{d}_{o n \_1}$ and $\widetilde{d}_{0 n \_2}$ is ignored, then the condition of $\widetilde{d}=\widetilde{d}_{o n \_1}=\widetilde{d}_{o n \_2}$ is satisfied. From Equation (6), the output current to duty cycle transfer function of the proposed fourth-order model $G_{d t 4}$ is shown as

$$
G_{d t 4}(s)=\frac{\widetilde{i}_{\mathrm{ac}}(s)}{\widetilde{d}(s)}=\frac{a_{2} s^{2}+a_{1} s+a_{0}}{s^{4}+b_{3} s^{3}+b_{2} s^{2}+b_{1} s+b_{0}}
$$

when the two flyback converters' parameters are identical, the fourth-order model $G_{d t 4}$ is reduced to a third-order model $G_{d t 3 \_} 1$.

$$
G_{d t 3 \_1}(s)=\frac{\widetilde{i}_{\mathrm{ac}}(s)}{\widetilde{d}(s)}=\frac{c_{1} s+c_{0}+c_{0}^{\prime}}{s^{3}+\left(j_{2}+f_{2}\right) s^{2}+\left(j_{1}+f_{1}\right) s+\left(j_{0}+f_{0}\right)}
$$

\subsubsection{The Third-Order Model Based on Single-Phase Flyback Converter}

For the sake of simplification, by assuming the two flyback converters identical and connected in parallel, some researchers have treated the dual-flyback micro-inverter as a single-phase flyback 
micro-inverter [23]. The third-order model $G_{d t 3 \_2}$ based on a single-phase flyback converter is studied instead of $G_{d t 3 \_1}$, which is expressed as

$$
G_{d t 3 \_2}(s)=\frac{\widetilde{i}_{\mathrm{ac}}(s)}{\widetilde{d}(s)}=\frac{c_{1} s+c_{0}}{s^{3}+j_{2} s^{2}+j_{1} s+j_{0}}
$$

\subsubsection{The Second-Order Model Based on Average Small Signal}

The second-order model based on a voltage-controlled current source is studied in [16,19,37-41]. This model is applied to reduce current stress and THDs and improve system efficiency. The second-order model is expressed as

$$
G_{d 2}=\frac{\widetilde{i}_{a c}}{\widetilde{d}}=\frac{h_{2}}{s^{2}+h_{1} s+h_{0}}
$$

where the parameters $a_{2} \sim a_{0}, b_{3} \sim b_{0}, c_{1} \sim c_{0}, c_{0}^{\prime}, j_{2} \sim j_{0}, f_{2} \sim f_{0}$ and $h_{2} \sim h_{0}$ are given in Appendix A.

Comparing Equations (9) and (10), the second-order model is further simplified. The equivalent parasitic resistances $R_{p 1}, R_{p 2}, R_{s 1}$ and $R_{s 2}$ of transformer magnetizing inductance are ignored. The model $G_{d 2}$ can only accurately predict the low-frequency behavior of the converter, but the model $G_{d t 3 \_2}$ can precisely predict the behavior of the converter at high and low frequencies [22], so the model $G_{d t 3 \_2}$ has more accuracy. On the other hand, $G_{d t 3 \_1}$ is much more accurate than $G_{d t 3 \_2}$ since the coupling terms $c_{0}^{\prime}, f_{2}, f_{1}$ and $f_{0}$ between dual-flyback are considered. In addition, $G_{d t 4}$ is better than $G_{d t 3 \_1}$ since parameter mismatch is taken into account. Therefore, with all that analysis, the sequence of models' accuracy is $G_{d t 4}>G_{d t 3 \_1}>G_{d t 3 \_2}>G_{d 2}$.

On the other hand, in the second-order model $G_{d 2}$ and in the third-order model $G_{d t 3 \_2}$, the primary magnetizing inductance currents $i_{m 1}$ and $i_{m 2}$ are not used as state variables. Therefore, these two models cannot be used to control the primary current to achieve current sharing. The proposed model $G_{d t 4}$ in this paper shows the parameter inconsistency and coupling between the two flybacks, which are the major sources of the current imbalance between the two flybacks. Meanwhile, the model takes $i_{m 1}$ and $i_{m 2}$ into account. Thus, it should be able to supply a solid basis to meet the current sharing requirement. Plus, a model-based current balance control strategy could be developed based on the proposed model.

\section{Current Controller Using Sliding Mode Control}

In this section, to solve the output imbalance between the two flybacks caused by coupling, parameter inconsistency and disturbance, a novel sliding mode control (SMC) current controller is designed, since the SMC would realize good dynamic response, strong robustness and good regulation performance [42-45]. In this paper, the SMC current sharing controller is constructed based on the presented accurate fourth-order mathematical model, and the target of current sharing is realized by controlling the primary currents of dual-flyback converters to regulate the duty cycles of switches $Q_{1}$ and $\mathrm{Q}_{2}$. The flow chart for designing the sliding mode current sharing controller are shown in Figure 4 .

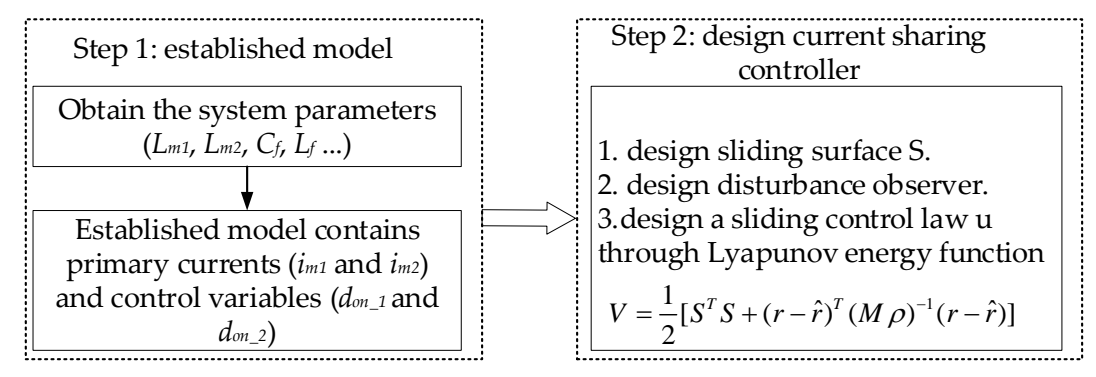

Figure 4. Flow chart for designing sliding mode current sharing controller. 
According to Figure 4, the design steps of SMC are as follows:

Step 1: A stable sliding surface is selected. Equation (6) can be written in matrix form as

$$
u=A \dot{x}+B x+r
$$

where $x=\left[\begin{array}{ll}i_{m 1} & i_{m 2}\end{array}\right]^{T}, u=\left[\begin{array}{ll}d_{o n} 1 & d_{o n \_}\end{array}\right]^{T}, r$ is the external disturbances of the input and output voltages. The parameters of matrix $A, B$ and $r$ are given in Appendix A.

$e_{1}$ and $e_{2}$ are defined as the current tracking errors of Flyback 1 and Flyback 2, respectively. Meanwhile, $e$ is defined as the error vector, $e=\left[\begin{array}{ll}e_{1} & e_{2}\end{array}\right]^{T}$. The tracking error dynamics are

$$
\begin{aligned}
& e_{1}=I_{1 r e f}-i_{m 1} \\
& e_{2}=I_{2 r e f}-i_{m 2}
\end{aligned}
$$

where, $I_{1 \text { ref }}$ and $I_{2 r e f}$ are the primary currents references of the Flyback 1 and Flyback 2 converters, respectively, which are given in $[16,19]$.

According to Equations (11) and (12), the current tracking errors dynamic can be written as:

$$
\dot{e}=\dot{I}_{r e f}-A^{-1}(u-r-B x)
$$

where, the reference current $I_{\text {ref }}$ is denoted as $\left[I_{1 \text { ref }} I_{2 r e f}\right]^{T}$. Let current sharing error $\alpha$ between two circuits be presented as $\left(e_{1}-e_{2}\right)$. Then the error matrix $\left[e_{1} e_{2} \alpha\right]^{T}$ would be calculated from individual tracking error by using the following transformation $F$ :

$$
\left[\begin{array}{lll}
e_{1} & e_{2} & \alpha
\end{array}\right]^{T}=F e
$$

where $F=\left[\begin{array}{ccc}1 & 0 & 1 \\ 0 & 1 & -1\end{array}\right]^{T}$

The overall objective of the controller is to minimize all the errors presented in Equation (14), namely the current tracking error and the current sharing error of the interleaved flyback circuit. Then a $3 \times 1$ dimensional sliding surface $S$ is defined as:

$$
S=\left[\begin{array}{lll}
S_{1} & S_{2} & S_{3}
\end{array}\right]^{T}=\lambda F e
$$

where $\lambda=\operatorname{diag}\left(\lambda_{1}, \lambda_{2}, \lambda_{3}\right)$ is the sliding coefficient, it defines the convergence speed of the errors on the sliding surface.

Step 2: The disturbance observer is designed. To ensure the controller has good robustness and the system has zero steady-state error, the disturbance observer is designed by integrating the sliding surface. The disturbance observer is defined as

$$
\hat{r}=\left[\begin{array}{l}
\hat{r}_{1} \\
\hat{r}_{2}
\end{array}\right]=\rho \beta \int S d \tau=\rho \beta \lambda F \int e d \tau
$$

where $\rho$ is the observer gain matrix, which is a tuning variable for the sliding mode controller. $\beta$ is coefficient matrix for limiting integral gain. Additionally, only when the transfer matrix $\rho \beta$ satisfies the following conditions is the integration performed.

$$
\rho \beta=\left[\begin{array}{ccc}
\rho_{1} \beta_{1} & 0 & 0 \\
0 & \rho_{2} \beta_{2} & 0
\end{array}\right]
$$

Step 3. A stable SMC control law is derived (Barbalat Lemma [46]). 
The stable SMC control law is presented as

$$
u=A \dot{I}_{r e f}+B x+\hat{r}+F^{-1} \lambda^{-1} K S
$$

where the matrix $K=\operatorname{diag}\left(K_{1}, K_{2}, K_{3}\right)$ is a positive definite feedback gain matrix. The stability of the system and errors asymptotically converge to the origin point, as proved in Appendix $B$.

Substituting Equation (16) into Equation (18), the synchronization sliding control law shown in Equation (18) is revised. The modified sliding control law is:

$$
\begin{aligned}
u & =A \dot{I}_{r e f}+B x+\overbrace{\rho \beta \int S d \tau}^{\text {IntegralGain }}+\overbrace{F^{-1} \lambda^{-1} K S}^{\text {proportionalGain }} \\
& =A \dot{I}_{r e f}+B x+S(k p, s m c+k i, s m c / s)
\end{aligned}
$$

where, $F^{-1}$ is the pseudo-inverse of $F$.

Equation (19) indicates the sliding mode control law $\mathrm{u}$ is made up of two items, $\left(A \dot{I}_{r e f}+B x\right)$ and $(k p, s m c+k i, s m c / s)$. The first item presents as feed-forward, which can improve the tracking bandwidth and reject the measured disturbance, the parameters $A$ and $B$ of $\left(A \dot{I}_{r e f}+B x\right)$ can be obtained from system parameters. The second item can present as PI gain, so there are only two parameters $k_{p, s m c}$ and $k_{i, s m c}$ need to design. In other words, the proposed sliding mode current sharing controller converts the control problem of multiple PI controllers into a single PI controller, reducing complexity of design.

\section{Simulation}

To prove the validity and feasibility of the proposed model and controller, the dynamic performance is compared with the PI current control by MATLAB/Simulink (2016b, MathWorks, Natick, MA, USA). A $250 \mathrm{~W}$ digitally controlled DCM interleaved flyback micro-inverter prototype is designed, where each flyback circuit is $125 \mathrm{~W}$, and the PV output voltage is $20 \mathrm{~V}-55 \mathrm{~V}$. The system parameters of the interleaved flyback micro-inverter are shown in Table 2, where the inductances of the transformer secondary side are $216 \mathrm{uH}$, and $P_{0}$ is the rated power of the interleaved flyback micro-inverter.

Table 2. System parameters.

\begin{tabular}{cccc}
\hline Parameters & Value & Parameters & Value \\
\hline$C_{P V}$ & $11 \mathrm{mF}$ & $R_{p 1}, R_{p 2}$ & $0.15 \Omega$ \\
$L_{m 1}, L_{m 2}$ & $6 \mu \mathrm{H}$ & $R_{s 1}, R_{s 2}$ & $0.05 \Omega$ \\
$C_{f}$ & $0.68 \mu \mathrm{F}$ & $R_{f}$ & $0.29 \Omega$ \\
$L_{f}$ & $600 \mu \mathrm{H}$ & $V_{\mathrm{g}}$ & $220 \mathrm{~V}$ \\
$\mathrm{n}$ & 6 & $f_{\mathrm{g}}$ & $50 \mathrm{~Hz}$ \\
$f_{s}$ & $100 \mathrm{kHz}$ & $P_{0}$ & $250 \mathrm{~W}$ \\
\hline
\end{tabular}

The control diagrams of SMC and PI current controller are illustrated in Figures 5 and 6, respectively. Figure 5 demonstrates the proposed sliding mode current sharing control adopts an open-loop control. The current sharing is achieved through sensing and controlling the primary switch currents. In order to meet the consistency of the comparison conditions, the current open-loop control mode is adopted in the conventional PI current sharing controller; the PI control diagram is indicated in Figure 6. It shows the PI current sharing controller consists of 3 PI controllers, which increases the design complexity. The designed sliding mode control law $\mathrm{u}$ is presented as Equation (17), the parameters matrix $A, B$ can be obtained from the system parameters. From Equation (19), the coefficients of $k_{p, s m c}$ and $k_{i, s m c}$ refer to $F^{-1} \lambda^{-1} K$ and $\rho \beta$, respectively. In order to meet the condition 
of asymptotic convergence, the parameters of $F^{-1} \lambda^{-1} K$ and $\rho \beta$ are obtained from $\rho=I, \beta_{1}=0.08$, $\beta_{2}=0.08, \lambda=I$ and $K=\mathrm{I}$, where $\mathrm{I}$ is the unit matrix.

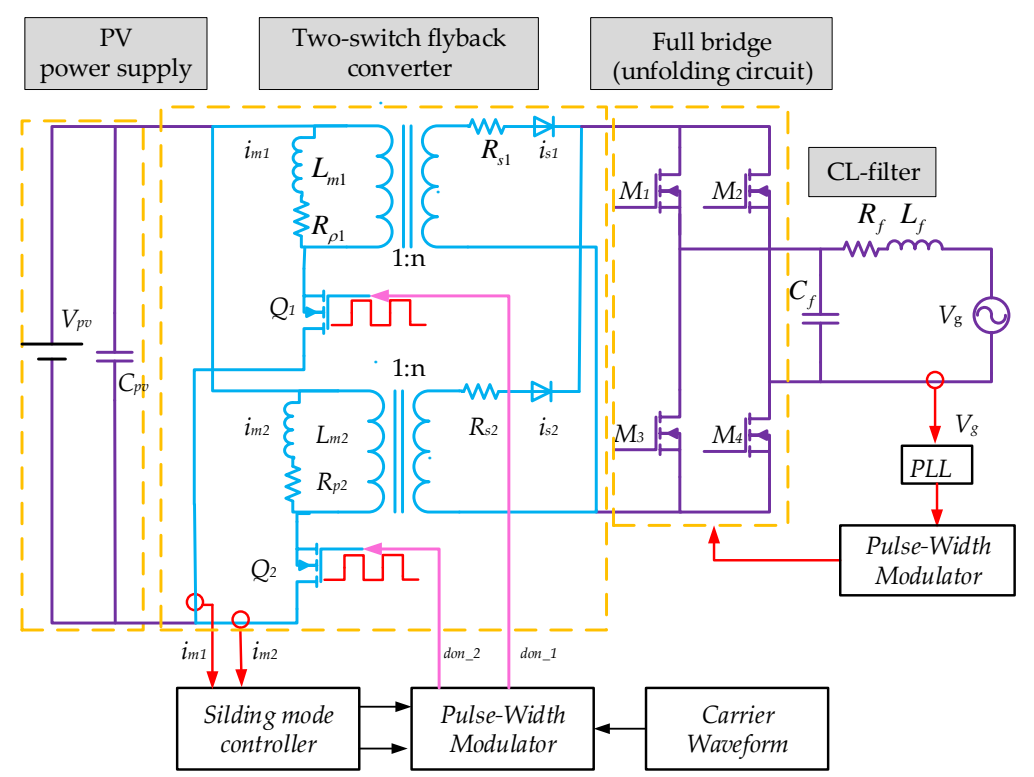

Figure 5. The SMC control diagram of interleaved flyback micro-inverter in DCM.

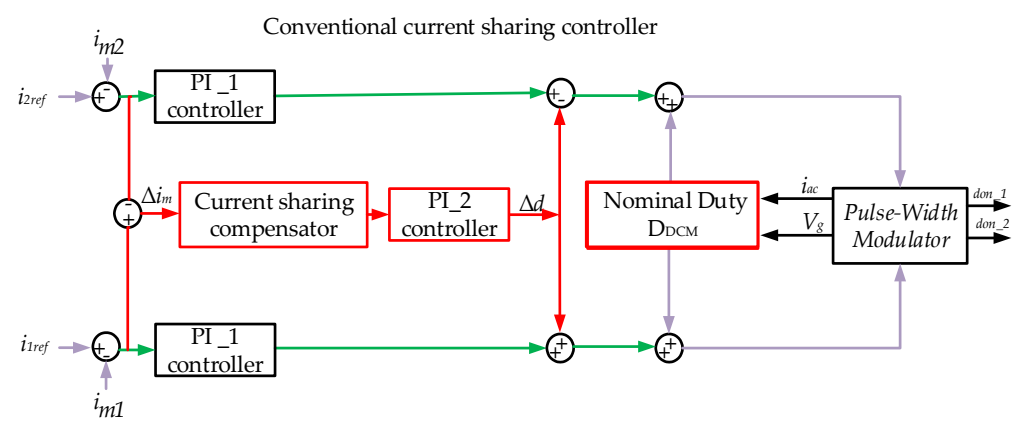

Figure 6. The PI control diagram of interleaved flyback micro-inverter in DCM.

In order to compare dynamic performances between the PI current sharing and the proposed sliding mode current sharing controller, the two cases are designed as follows. The output voltage $V_{\text {rms }}$ is $220 \mathrm{~V}$ :

Case 1: The two converters, Flyback 1 and Flyback 2, have the same parameters in the flyback micro-inverter. The output power $P_{\text {out }}$ is changed from $200 \mathrm{~W}\left(80 \% P_{0}\right)$ to $125 \mathrm{~W}\left(50 \% P_{0}\right)$ at $0.06 \mathrm{~s}$.

Figure 7 shows the waveform of the output grid current $i_{a c}$ and reference signal $i_{a c \_r e f}$ of the interleaved flyback micro-inverter with the PI current sharing controller. There are large current ripples in simulation's waveform. When the output power decreases to $50 \% P_{0}$, the PI controller regulates the output current to track the desired output current, which shows the ability to reject the disturbance, but oscillation still exists. Through the Fast Fourier Transformation (FFT) analysis, when $0.02 \mathrm{~s} \leq t \leq 0.06 \mathrm{~s}$, the THDs of output current is $6.43 \%$; when $0.06 \mathrm{~s}<t \leq 0.1 \mathrm{~s}$, the THDs of output current is $6.58 \%$. 


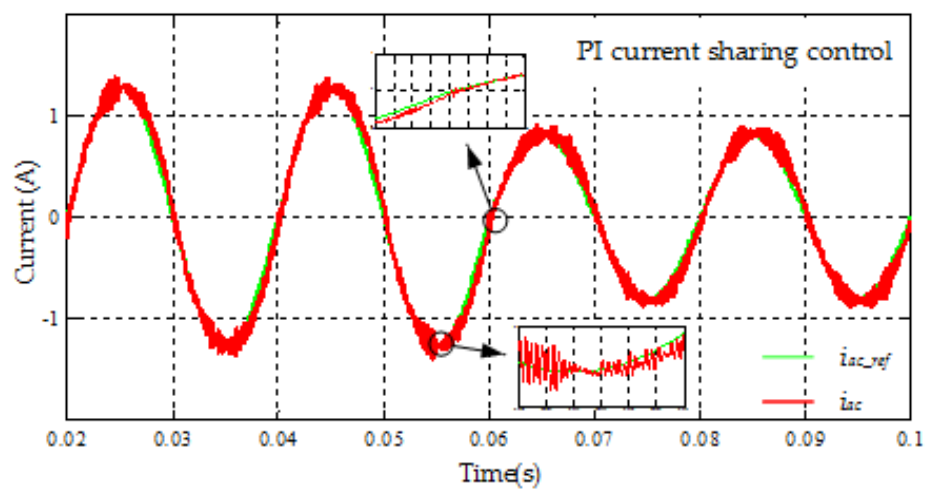

Figure 7. Simulation results of case 1: output grid current response of the interleaved flyback micro-inverter controlled by a PI controller.

Figure 8 shows the waveforms of the output grid current $i_{a c}$ of the interleaved flyback micro-inverter and reference signal $i_{a c_{-} \_f}$ with the sliding mode current sharing controller. When the output power $P_{\text {out }}$ changes from $80 \% P_{0}$ to $50 \% P_{0}$, the effective value of the output current $i_{a c}$ is from $0.908 \mathrm{~A}$ to $0.565 \mathrm{~A}$, where only a small transient current is observed in the current waveforms. Through the FFT analysis, when $0.02 \mathrm{~s} \leq t \leq 0.06 \mathrm{~s}$, the output current THDs of the SMC controller is $2.97 \%$; when $0.06 \mathrm{~s}<t \leq 0.1 \mathrm{~s}$, the output current THDs of the SMC controller is $2.45 \%$.

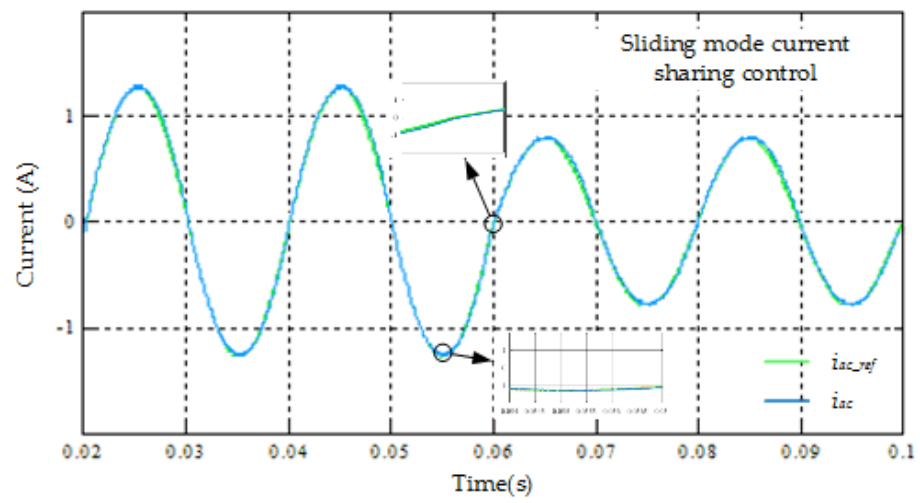

Figure 8. Simulation results of case 1: output grid current response of the interleaved flyback micro-inverter controlled by a SMC controller.

The simulation results show that the proposed SMC controller has stronger robustness to solve the output imbalance caused by disturbance when the output power decreases. Moreover, compared with the PI controller, the output current $i_{a c}$ of the proposed SMC controller has lower THDs.

Case 2: The two converters, Flyback 1 and Flyback 2, have different parameters in the flyback micro-inverter. The output power $P_{\text {out }}$ is also changed from $200 \mathrm{~W}\left(80 \% P_{0}\right)$ to $125 \mathrm{~W}\left(50 \% P_{0}\right)$ at $0.06 \mathrm{~s}$. The different parameters are given in Table 3.

Table 3. Different system parameters.

\begin{tabular}{cccccc}
\hline Parameters & Value & Parameters & Value & Parameters & Value \\
\hline$L_{m 1}$ & $5.8 \mu \mathrm{H}$ & $R_{p 1}$ & $0.15 \Omega$ & $R_{s 1}$ & $0.051 \Omega$ \\
$L_{m 2}$ & $6.2 \mu \mathrm{H}$ & $R_{p 2}$ & $0.18 \Omega$ & $R_{s 2}$ & $0.085 \Omega$ \\
$L_{s 1}$ & $216 \mu \mathrm{H}$ & $L_{s 2}$ & $223 \mu \mathrm{H}$ & - & - \\
\hline
\end{tabular}


Figure 9 describes the waveform of the output grid current $i_{a c}$ of the interleaved flyback micro-inverter using the PI current sharing controller, which tracks the reference current $I_{\text {ref }}$ well. The output current ripple becomes large when the output current is biggest. As the output power reduces to $50 \% P_{0}$, the output current stays away from the balance point and then converges in short time. Through the FFT analysis, when $0.02<t<0.06$, the output current THDs of the PI controller are $6.85 \%$; when $0.06 \leq t \leq 0.1 \mathrm{~s}$, the output current THDs of the PI controller are $6.87 \%$.

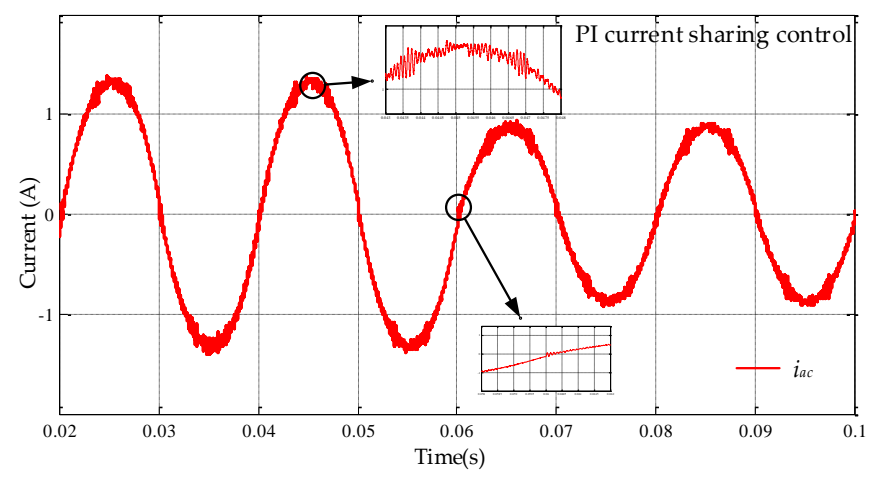

Figure 9. Simulation results of Case 2: output gird current response of interleaved flyback micro-inverter by a PI controller.

Figure 10 shows the waveform of the output grid current $i_{a c}$ of interleaved flyback micro-inverter using the proposed sliding mode current sharing controller. There is a small current transient when output power decreases to $125 \mathrm{~W}$. Through the FFT analysis, when $0.02<t<0.06$, the THD of output current is $3.44 \%$; when $0.06 \leq t \leq 0.1 \mathrm{~s}$, the THD of output current is $2.83 \%$. The results of Figures 9 and 10 confirm that SMC has better robustness than the PI controller when a parameter imbalance exists.

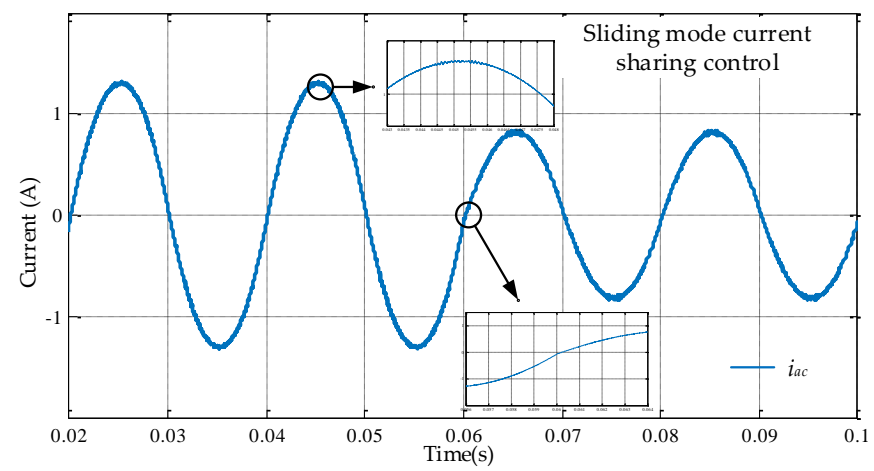

Figure 10. Simulation results of Case 2: output gird current response of interleaved flyback micro-inverter by a SMC controller.

Figure 11a,b demonstrates the waveforms of primary currents $i_{m 1}$ and $i_{m 2}$ with the PI controller, and those with the sliding mode controller, respectively. It is very clear that the peak current difference between the two primary currents is about $0.318 \mathrm{~A}$ with the PI current sharing control, while that with the sliding mode controller is much less, and its value is approximate $0.05 \mathrm{~A}$. From the results, it is found that the proposed controller achieved better current sharing in comparison to the PI controller, which would avoid one of the converters being overloaded, resulting in lower efficiency and reliability of the system, and even reducing the life of hardware. Figure 12 shows the current sharing errors after two current sharing controllers, and the results indicate that the current sharing errors with both controllers are almost negligible, but the THDs of the output current with the PI controller are bigger. 

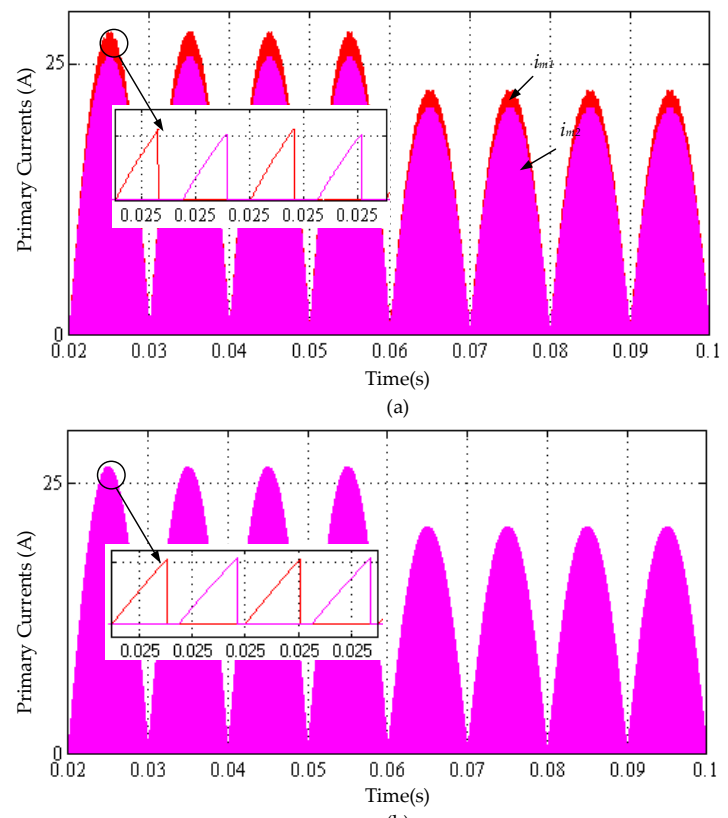

(b)

Figure 11. Waveforms for primary currents by two current sharing controllers: (a) PI current sharing control; (b) sliding mode current sharing control.
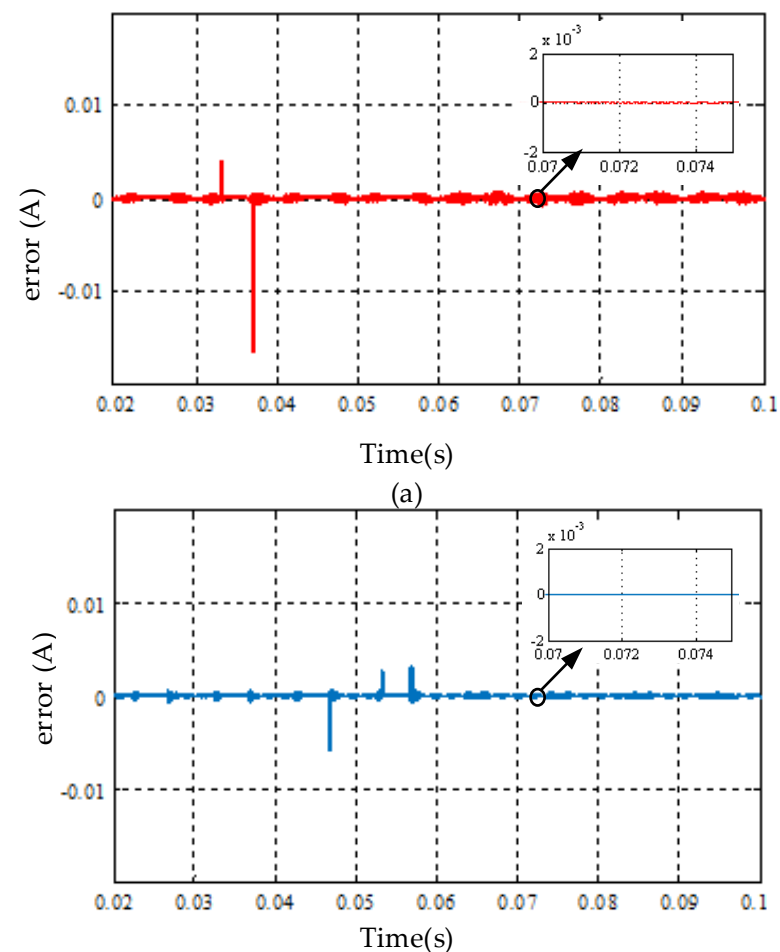

(b)

Figure 12. The difference of the two primary currents after the two current sharing controllers: (a) PI current sharing control; (b) sliding mode current sharing control.

In summary, the simulation results show that the proposed SMC has good robustness to solve output imbalance caused by coupling, parameter inconsistency and disturbance. No matter whether the parameters are identical or not, compared with the PI current sharing controller, the proposed SMC tracks a sinusoidal reference effectively and achieves current sharing. Simultaneously, it has stronger 
anti-interference ability when the load power changes. In addition to that, there is a lower THD of $i_{a c}$ when the proposed SMC is applied. The detailed simulation results are presented in Table 4.

Table 4. Simulink results.

\begin{tabular}{cccccc}
\hline \multirow{2}{*}{ Controller } & \multirow{2}{*}{ Pout } & \multicolumn{2}{c}{ Case 1 } & \multicolumn{2}{c}{ Case 2 } \\
\cline { 3 - 6 } & & $\alpha$ & THDs & $\alpha$ & THDs \\
\hline the proposed SMC & $200 \mathrm{~W}$ & 0.001 & $2.97 \%$ & 0.01 & $3.44 \%$ \\
PI controller & $200 \mathrm{~W}$ & 0.01 & $6.43 \%$ & 0.32 & $6.85 \%$ \\
the proposed SMC & $150 \mathrm{~W}$ & 0.001 & $2.45 \%$ & 0.05 & $2.83 \%$ \\
PI controller & $150 \mathrm{~W}$ & 0.005 & $6.58 \%$ & 0.318 & $6.87 \%$ \\
\hline
\end{tabular}

\section{Conclusions}

This paper has proposed a current sharing control approach for the DCM interleaved flyback micro-inverter. To do this, an accurate fourth-order model has firstly been built up, which is used to analyze the output imbalance problem caused by coupling and mismatched parameters between two flyback converters, such as the equivalent series resistances and magnetizing inductances of the primary/secondary magnetizing inductance. The accuracy of the proposed model has been analyzed through comparing it to the third-order and second-order models, and the analysis results have shown that the proposed model is more accurate than the existing models.

Then, a sliding mode current sharing controller based on the full-fourth-order model has been developed, which solves the output imbalance caused by parameter imbalance and disturbance. The developed sliding mode controller comprises two parts: the feed-forward part, which can improve the tracking bandwidth and reject the measured disturbance, and the feedback part, which is in a form of PI. Thus, the proposed sliding mode controller can use the conventional PI blocks for current sharing. Since the parameters of the sliding control law can be designed by the proposed model and Lyapunov energy function, it is convenient to design compared to the PI current sharing controllers with four gains.

Finally, simulation studies were carried out in MATLAB/Simulink to validate the model accuracy, and the sliding mode current sharing controller. Results showed that the sliding mode controller tracks sinusoidal reference signals smoothly, and controls the current sharing between two flyback converters effectively when compared to the PI controllers.

Author Contributions: All the author contributed to this work. X.T. designed this study, analysis, implemented simulations, and wrote the first draft of the paper. M.D. and L.W. contributed the project administration and checked the overall logic of this work. D.S. contributed to providing important suggestions and writing-review. L.L. contributed to giving helpful suggestions for simulations and English grammar. M.Z. contributed to the discussion of this study.

Funding: This work was supported in part by National Natural Science Foundation of China (Grant NO.51677194).

Conflicts of Interest: The authors declare no conflict of interest.

\section{Nomenclature}

$\begin{array}{lll}C p v & \text { input capacitor } & \mathrm{mF} \\ V_{p v} & \text { PV voltage } \\ \mathrm{n} & \begin{array}{l}\mathrm{V} \\ \text { the transformer turns ratio } \\ L_{m 1}, L_{m 2}\end{array} & - \\ i_{m 1}, i_{m 2} & \begin{array}{l}\text { the primary magnetizing inductances of the } \\ i_{s 1}, i_{s 2}\end{array} & \mathrm{uH} \\ L_{f} & \text { the primary currents of the transformer } & \mathrm{A} \\ C f & \text { the secondary currents of the transformer } & \mathrm{A} \\ & \text { the filter inductor } & \mathrm{uH} \\ & \text { filter capacitor } & \mathrm{uH}\end{array}$




$R_{p 1}, R_{p 2}$
$R_{s 1}, R_{s 2}$
$R_{\mathrm{f}}$
$i_{a c}$
$i_{a c \_r e f}$
$f \mathrm{~s}$
$f \mathrm{~g}$
$V \mathrm{~g}$
$P_{0}$
$\mathrm{D}$

$\bar{x}, \widetilde{x}$

$H$

$\mathrm{A}_{k}$ and $\mathrm{B}_{k}$

$d_{i(i=1, \ldots, k)}$

$\Phi$

$n_{L}$

$d_{o n \_1}, d_{o n \_2}$

$d_{o f f \_} 1, d_{o f f \_} 2$

$A_{D C M}, B_{D C M}, W_{D C M}$

$G_{d t 4}, G_{d t 3 \_1}, G_{d t 3 \_2}, G_{d 2}$
ESRs of the primary magnetizing inductance

$\Omega$

ESRs of the secondary magnetizing inductance $\quad \Omega$

ESR of the output filter inductor $\quad \Omega$

output current A

the reference of $i_{a c} \quad \mathrm{~A}$

switching frequency $\quad \mathrm{kHZ}$

frequency of gird $\quad \mathrm{HZ}$

grid voltage $\mathrm{V}$

rated power W

main MOSFET duty cycle

the average and small signal of $x$ in one

switching period

the number of steady-state subinterval

steady state equations in $\mathrm{k}$-interval

k-interval duty cycle

revised matrix

the number of inductor

duty cycles of switches $Q_{1}$ and $Q_{2}$ when they

are on

the time intervals from turn-off of switches Q1

and Q2 to the decreasing to zero of transformer inductor currents

The coefficient matrixes of the proposed model The transfer functions of the proposed fourthorder model, the reduced to third-order model, the third-order model based on single-phase

flyback converter and second-order model

$a_{2} \sim a_{0}, b_{3} \sim b_{0}, c_{1} \sim \mathcal{c}_{0}, c_{0}^{\prime}, j_{2}$ the coefficients of $G_{d t 4}, G_{d t 3 \_1}, G_{d t \_2}$ and $G_{d 2}$

$\sim j_{0}, f_{2} \sim f_{0}, h_{2} \sim h_{0}$

$e_{1} e_{2}$

tracking errors of Flyback1 and Flyabck2

A

current sharing error

A

the primary current references of Flyback 1 and Flyback2 converters

A the sliding surface

sliding coefficient

$\rho \quad$ observer gain matrix

$\beta \quad$ coefficient matrix for limiting integral gain

$K \quad$ positive definite feedback gain matrix -

$k_{p, s m c}, k_{i, s m c} \quad$ proportional and integral of sliding mode law

$\Omega$
A
A
$\mathrm{kHZ}$
$\mathrm{HZ}$
$\mathrm{W}$
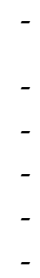

$-$
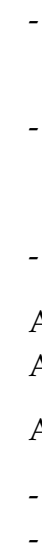

\section{Appendix A.}

The parameters $A_{D C M}, B_{D C M}$ and $W_{D C M}$ of Equation (6) are given

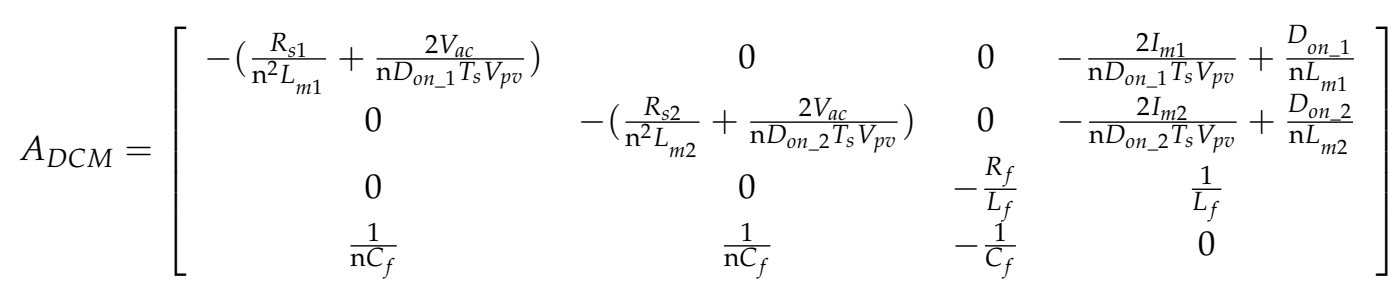




$$
\begin{aligned}
& B_{D C M}=\left[\begin{array}{c}
\frac{2 I_{m 1} V_{a c}}{\mathrm{n} D_{o n \_1}^{2} T_{s} V_{p v}}-\frac{D_{o n_{\_} 1} T_{s} V_{p v}\left(R_{\rho 1}-\frac{R_{s 1}}{\mathrm{n}^{2}}\right)}{L_{m 1}^{2}}+\frac{V_{a c}}{\mathrm{n} L_{m 1}}+\frac{V_{p v}}{L_{m 1}} \\
\frac{2 I_{m 2} V_{a c}}{\mathrm{n} D_{o n \_2}^{2} T_{s} V_{p v}}-\frac{D_{o n_{-} 2} T_{s} V_{p v}\left(R_{\rho 2}-\frac{R_{s 2}}{\mathrm{n}^{2}}\right)}{L_{m 2}^{2}}+\frac{V_{a c}}{\mathrm{n} L_{m 2}}+\frac{V_{p v}}{L_{m 2}} \\
0 \\
-\frac{T_{s} V_{p v}}{\mathrm{n} C_{f}}\left(\frac{D_{o n \_}}{L_{m 1}}+\frac{D_{o n \_}}{L_{m 2}}\right)
\end{array}\right]
\end{aligned}
$$

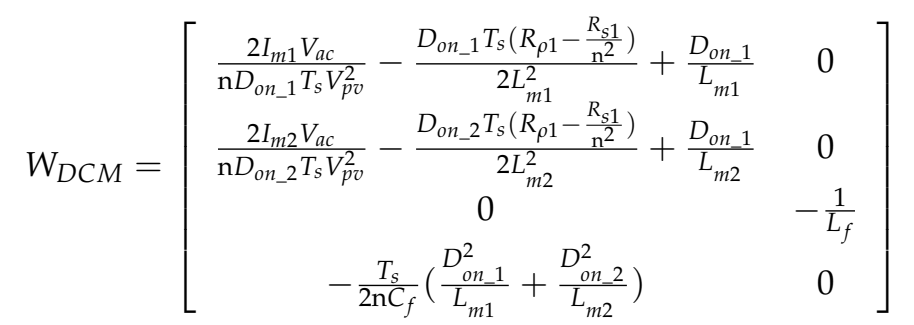

The coefficient parameters $a_{2} \sim a_{0}, b_{3} \sim b_{0}$ of $G_{d t 4}, c_{1} \sim c_{0}, j_{2} \sim j_{0}$ and $f_{2} \sim f_{0}$ of $G_{d t 3 \_}$, and $h_{2} \sim h_{0}$ of $G_{d 2}$ are given as.

$$
\begin{aligned}
& \eta_{1}=\frac{R_{s 1}}{\mathrm{n}^{2} L_{m 1}}+\frac{2 V_{a c}}{\mathrm{nD} T_{s} V_{p v}} \\
& \eta_{2}=\frac{R_{s 2}}{\mathrm{n}^{2} L_{m 2}}+\frac{2 V_{a c}}{\mathrm{nD} T_{s} V_{p v}} \\
& \eta_{3}=-\frac{2 I_{m 1}}{\mathrm{nD} T_{s} V_{p v}}+\frac{\mathrm{D}}{\mathrm{n} L_{m 1}} \\
& \eta_{4}=-\frac{2 I_{m 2}}{\mathrm{nD} T_{s} V_{p v}}+\frac{\mathrm{D}}{\mathrm{n} L_{m 2}}
\end{aligned}
$$

- $\quad a_{2} \sim a_{0}$ :

$$
\begin{aligned}
& a_{2}=\frac{\mathrm{D} T_{s} V_{p v}}{\mathrm{n} C_{f} L_{f}}\left(\frac{L_{m 1}+L_{m 2}}{L_{m 1} L_{m 2}}\right) \\
& a_{1}=\frac{-\mathrm{D} T_{s} V_{p v} L_{m 2}\left(R_{\rho 1}-\frac{R_{s 1}}{\mathrm{n}^{2}}\right)+\mathrm{D} T_{s} V_{p v} L_{m 1}\left(R_{\rho 2}-\frac{R_{s 2}}{\mathrm{n}^{2}}\right)}{\mathrm{n} C_{f} L_{f} L_{m 1} L_{m 2}}+\frac{\mathrm{D} T_{s} V_{p v}}{\mathrm{n} f_{f} L_{f}}\left(\frac{L_{m 1}+L_{m 2}}{L_{m 1} L_{m 2}}\right)\left(\frac{R_{s 1}}{\mathrm{n}^{2} L_{m 1}}+\frac{R_{s 2}}{\mathrm{n}^{2} L_{m 2}}+\frac{4 V_{a c}}{\mathrm{nDD} T_{s} V_{p v}}\right) \\
& +\frac{2\left(I_{m 1}-I_{m 2}\right) V_{a c}}{\mathrm{n}^{2} \mathrm{D} 2 T_{s} V_{p v} C_{f} L_{f}}+\frac{\left(\frac{V_{a c}}{n}+V_{p v}\right)\left(L_{m 2}-L_{m 1}\right)}{\mathrm{n} C_{f} L_{f} L_{m 1} L_{m 2}} \\
& a_{0}=\frac{2 \eta_{2} I_{m 1} V_{a c}}{\mathrm{n}^{2} \mathrm{D} 2 T_{s} V_{p v} C_{f} L_{f}}-\frac{\mathrm{D} T_{s} V_{p v} \eta_{2}\left(R_{\rho 1}-\frac{R_{s 1} 1}{\mathrm{n}^{2}}\right)}{\mathrm{n} L_{m 1} C_{f} L_{f}}+\frac{\eta_{2} V_{a c}+\mathrm{n} \eta_{2} V_{p v}}{\mathrm{n}^{2} L_{m 1} C_{f} L_{f}}+\frac{\eta_{1}+\eta_{2}}{L_{f}}\left(\frac{2 I_{m 2} V_{a c}}{\mathrm{nD} 2 T_{s} V_{p v}}-\frac{\mathrm{D} T_{s} V_{p v}\left(R_{\rho 2}-\frac{R_{s 2}}{\mathrm{n}^{2}}\right)}{L_{m 2}}+\frac{V_{a c}}{\mathrm{n} L_{m 2}}\right. \\
& \left.+\frac{V_{p v}}{L_{m 2}}+\frac{\mathrm{D}_{s} V_{p v}}{\mathrm{nC}_{f}}\left(\frac{L_{m 1}+L_{m 2}}{L_{m 1} L_{m 2}}\right)\right)
\end{aligned}
$$

- $b_{3} \sim b_{0}$ :

$$
\begin{gathered}
b_{3}=\eta_{1}+\eta_{2}+\frac{R_{f}}{L_{f}} \\
b_{2}=-\frac{\left(\eta_{3}+\eta_{4}\right) L_{f}}{\mathrm{n} C_{f}}+\frac{1}{L_{f} C_{f}}+\eta_{1} \eta_{2}+\frac{R_{f}\left(\eta_{1}+\eta_{2}\right)}{L_{f}} \\
b_{1}=-\frac{\left(\eta_{1} \eta_{4}+\eta_{2} \eta_{3}\right) L_{f}+\left(\eta_{3}+\eta_{4}\right) R_{f}-\mathrm{n}\left(\eta_{1}+\eta_{2}\right)-\mathrm{n} \eta_{1} \eta_{2} R_{f} C_{f}}{\mathrm{n} C_{f} L_{f}} \\
b_{0}=-\frac{\left(\eta_{2} \eta_{3}+\eta_{1} \eta_{4}\right) R_{f}-\mathrm{n}\left(\eta_{1} \eta_{2}\right)}{\mathrm{n} C_{f} L_{f}}
\end{gathered}
$$

- $\quad c_{1} \sim c_{0}:$

$$
c_{1}=-\frac{\mathrm{D} T_{\mathrm{s}} V_{p v}}{\mathrm{n} L_{m 1} C_{f} L_{f}}
$$




$$
c_{0}=-\frac{\frac{\eta_{1}}{L_{m 1}}-\frac{V_{p v}}{L_{m 1}}-\frac{V_{a c}}{\mathrm{n} L_{m 1}}-\frac{\mathrm{D} T_{s}\left(R_{p 1}-\frac{R_{s 1}}{\mathrm{n}^{2}}\right)}{L_{m 1}^{2}}-\frac{2 I_{m 1} V_{a c}}{\mathrm{nD}^{2} T_{s} V_{p v}}}{\mathrm{n} L_{f} C_{f}}
$$

- $j_{2} \sim j_{0}$ :

$$
\begin{gathered}
j_{2}=\frac{R_{f}}{C_{f}}-\eta 3-\eta 1+\frac{R_{p 1}}{2}+\frac{R_{s 1}}{2 \mathrm{n}^{2} L_{m 1}}+\frac{\left(-\mathrm{D}^{2} L_{m 1} T_{s}{ }^{2} V_{p v}{ }^{2} \mathrm{n}^{2}+3 \mathrm{n} V_{a c} \mathrm{D}^{2} L_{m 1} T_{s} V_{p v}-2 \mathrm{n} I_{m 1} V_{a c} L_{m 1}\right)}{2 \mathrm{D}^{3} L_{m 1} T_{s}^{2} V_{p v}{ }^{2} \mathrm{n}^{2}} \\
j_{1}=\eta_{1} \eta_{3}+\frac{1}{C_{f} L_{f}}-\frac{\left(1+\mathrm{n} R_{f}\right)\left(\eta_{1}+\eta_{3}\right)}{\mathrm{n} C_{f}}-d_{0}{ }^{2}+\frac{d_{0}\left(\eta_{1}+\eta_{3}-\frac{R_{f}}{C_{f}}\right)}{2 \mathrm{D}^{3} L_{m 1} T_{s}^{2} V_{p v}{ }^{2} \mathrm{n}^{2}} \\
j_{0}=\frac{R_{f} \eta_{1} \eta_{3}}{L_{f}}-\frac{\eta_{1}+\eta_{3}}{C_{f} L_{f}}+\frac{2 \eta_{1} \eta_{3}+\frac{R_{f}}{C_{f}}\left(\eta_{1}+\eta_{3}\right)}{\mathrm{n} C_{f}}-d_{0} d_{1}+\frac{d_{1}\left(\eta_{1}+\eta_{3}-\frac{R_{f}}{C_{f}}\right)}{2 \mathrm{D}^{3} L_{m 1} T_{s}^{2} V_{p v}{ }^{2} \mathrm{n}^{2}}
\end{gathered}
$$

- $f_{2} \sim f_{0}$ :

$$
\begin{gathered}
f_{2}=\eta 3-\frac{R_{p 1}}{2}-\frac{R_{s 1}}{2 \mathrm{n}^{2} L_{m 1}}-\frac{\left(-\mathrm{D}^{2} L_{m 1} T_{s}^{2} V_{p v}^{2} \mathrm{n}^{2}+3 \mathrm{n} V_{a c} \mathrm{D}^{2} L_{m 1} T_{s} V_{p v}-2 \mathrm{n} I_{m 1} V_{a c} L_{m 1}\right)}{2 \mathrm{D}^{3} L_{m 1} T_{s}^{2} V_{p v}{ }^{2} \mathrm{n}^{2}} \\
f_{1}=-\eta_{1} \eta_{3}+\frac{\eta_{1}+\eta_{3}+\mathrm{n} R_{f}\left(\eta_{3}-\eta_{1}\right)}{\mathrm{n} C_{f}}+d_{0}^{2}-\frac{d_{0}\left(\eta_{1}+\eta_{3}-\frac{R_{f}}{C_{f}}\right)}{2 \mathrm{D}^{3} L_{m 1} T_{s}^{2} V_{p v}^{2} \mathrm{n}^{2}} \\
f_{0}=-\frac{R_{f} \eta_{1} \eta_{3}}{L_{f}}+\frac{\eta_{1}+\eta_{3}}{C_{f} L_{f}}-\frac{2 \eta_{1} \eta_{3}+\frac{R_{f}}{C_{f}}\left(\eta_{1}+\eta_{3}\right)}{\mathrm{n} C_{f}}+d_{0} d_{1}-\frac{a_{1}\left(\eta_{1}+\eta_{3}-\frac{R_{f}}{C_{f}}\right)}{2 \mathrm{D}^{3} L_{m 1} T_{s}^{2} V_{p v}^{2} \mathrm{n}^{2}}
\end{gathered}
$$

- $\quad h_{2} \sim h_{0}$ :

$$
\begin{gathered}
h_{2}=\mathrm{D}^{\prime 2} V_{p v}^{2} T_{s} /\left(C_{f} L_{f} L_{m 1} V_{a c}\right) \\
h_{1}=\left(L_{m 1} V_{0} C_{f} R_{f}+\frac{\mathrm{D}^{\prime 2} V_{p v}^{2} T_{s} L_{f}}{2 V_{a c}}\right) /\left(C_{f} L_{f} L_{m 1} V_{a c}\right) \\
h_{0}=\left(L_{m 1} V_{a c}+\frac{\mathrm{D}^{\prime 2} V_{p v}^{2} T_{s} R_{f}}{2 V_{a c}}\right) /\left(C_{f} L_{f} L_{m 1} V_{a c}\right)
\end{gathered}
$$

The parameters of matrix $A, B$ shown in Equation (11) are given as

$$
\begin{gathered}
A=\left[\begin{array}{cc}
a_{11} & 0 \\
0 & a_{12}
\end{array}\right] \\
a_{11}=\frac{2 I_{m 1} L_{m 1}^{2} V_{a c}-\mathrm{nD}^{3} T_{s}^{2} V_{p v}^{2}\left(R_{\rho 1}-\frac{R_{s 1}}{\mathrm{n}^{2}}\right)+V_{a c} \mathrm{D}^{2} T_{s} V_{p v} L_{m 1}+\mathrm{nD}^{2} T_{s} V_{p v}^{2} L_{m 1}}{\mathrm{nD}^{2} T_{s} V_{p v} L_{m 1}^{2}} \\
a_{12}=\frac{2 I_{m 2} L_{m 2}^{2} V_{a c}-\mathrm{nD}^{3} T_{s}^{2} V_{p v}^{2}\left(R_{\rho 2}-\frac{R_{s 2}}{\mathrm{n}^{2}}\right)+V_{a c} \mathrm{D}^{2} T_{s} V_{p v} L_{m 2}+\mathrm{nD}^{2} T_{s} V_{p v}^{2} L_{m 2}}{\mathrm{nD}^{2} T_{s} V_{p v} L_{m 2}^{2}} \\
B=\left[\begin{array}{cc}
\frac{a_{11}\left(\mathrm{D} T_{s} V_{p v} R_{s 1}+2 \mathrm{n} L_{m 1} V_{a c}\right)}{\mathrm{n}^{2} \mathrm{D} T_{s} V_{p v} L_{m 1}} & 0 \\
0 & \frac{a_{12}\left(\mathrm{D} T_{s} V_{p v} R_{s 2}+2 \mathrm{n} L_{m 2} V_{a c}\right)}{\mathrm{n}^{2} \mathrm{D} T_{s} V_{p v} L_{m 2}}
\end{array}\right]
\end{gathered}
$$




\section{Appendix B. Robustness of the Proposed SMC}

Remark 1. The Lyapunov energy function $V$ satisfies the condition of being lower bounded, so the $V$ is constructed as

$$
V=\frac{1}{2}\left[S^{T} S+(r-\hat{r})^{T}(M \rho)^{-1}(r-\hat{r})\right]>0
$$

It is assumed that the SMC controller for current sharing is stable in the interleaved flyback micro-inverter. $V$ represents the total energy of the system, which depends on the sliding surface dynamics by the $S^{T} S$ term, also depends on the adaptive disturbance error by the $(r-\hat{r})^{T}(M \rho)^{-1}(r-\hat{r})$ term.

Remark 2. The derivative of the Lyapunov function $\dot{\boldsymbol{V}}$ must be negative semi-definite to generate a stable SMC control law. As a result, asymptotic stability of the overall system may be achieved.

It should be noted that the disturbance is regarded as a slowly varying quantity, so that the derivative of the actual disturbance is considered to be zero, $\dot{r}=0$. Then, the derivative of the Lyapunov energy function is obtained from Equation (A31) and computed as:

$$
\begin{gathered}
\dot{V}=\frac{1}{2}\left[\dot{\boldsymbol{S}}^{T} \boldsymbol{S}+\boldsymbol{S}^{T} \dot{\boldsymbol{S}}+(\dot{r}-\dot{\hat{r}})^{T}(\boldsymbol{M} \rho)^{-1}(r-\hat{r})+(r-\hat{r})^{T}(\boldsymbol{M} \rho)^{-1}(\dot{r}-\dot{\hat{r}})\right] \\
=\boldsymbol{S}^{T} \dot{\boldsymbol{S}}-(r-\hat{r})^{T}(\boldsymbol{M} \rho)^{-1} \dot{\hat{r}}
\end{gathered}
$$

According to Equations (15) and (16), Equation (A32) can be expressed as

$$
\dot{V}=S^{T}\left[\lambda F \dot{I}_{r e f}-\lambda F A^{-1}(u-B x)\right]+S^{T} \lambda F A^{-1} \hat{r}+S^{T}\left(\lambda F-\beta^{T}\right) A^{-1}(r-\hat{r})
$$

In order to meet the requirement of $\dot{V}<0$, the matrix $\beta$ should be designed to satisfy the condition of $S^{T}\left(\lambda F-\beta^{T}\right) A^{-1}(r-\hat{r})<0$, which makes the disturbance observable. Next, to ensure the system asymptotically converges ( $\dot{V}$ satisfies the condition of negative semi-definite). Then the derivative of the Lyapunov energy function is designed as follows:

$$
\dot{V}=S^{T}\left[\lambda F \dot{I}_{r e f}-\lambda F A^{-1}(u-B x)\right]+S^{T} \lambda F A^{-1} \hat{r}=-S^{T} K S
$$

Substituting Equation (16) into Equation (A34), the SMC control law $u$ is obtained, which is given in Equation (18).

Remark 3. The $\dot{V}$ should satisfy the condition of being uniformly continuous in time, or $\ddot{V}$ should satisfy the condition of being bounded.

According to Equation (A34), the differential of $\dot{V}$ is given as

$$
\ddot{V}=-2 S^{T} K \dot{S}
$$

In order to satisfy the boundary condition, the $S$ and $\dot{S}$ should be bounded.

Next, let Equations (13) and (15) be substituted into Equation (A34), then

$$
\dot{S}+K S=\lambda F A^{-1}(r-\hat{r})
$$

From Equation (A36), it is shown that the sliding surface $S$ and differential of $S$ are bounded, since the term of $(r-\hat{r})$ is abounded. Therefore, it is proved that $\ddot{V}$ satisfies the condition of being 
bounded, since $S$ and $\dot{S}$ are bounded. So $\dot{V}$ satisfies the condition of being uniformly continuous in time.

According to Barbalat's lemma [46], when three remarks are satisfied, it ensures that all the errors can converge to the sliding surface. Finally, it is proved that the errors $e_{1}, e_{2}$ and $\alpha$ can converge to a zero point and the designed controller is stable.

\section{References}

1. Chiacchio, F.; Famoso, F.; D’Urso, D.; Brusca, S.; Aizpurua, J.I.; Cedola, L. Dynamic performance evaluation of photovoltaic power plant by stochastic hybrid fault tree automaton model. Energies 2018, 11, 306. [CrossRef]

2. Song, D.; Yang, J.; Fan, X.; Liu, Y.; Liu, A.; Chen, G.; Joo, Y. Maximum power extraction for wind turbines through a novel yaw control solution using predicted wind directions. Energy Convers. Manag. 2018, 157, 589-599. [CrossRef]

3. Huang, L.; Qiu, D.; Xie, F.; Chen, Y.; Zhang, B. Modeling and stability analysis of a single-phase two-stage grid-connected Photovoltaic System. Energies 2017, 10, 2176. [CrossRef]

4. Wang, Y.; Gan, C.; Ni, K.; Li, X.; Tang, H.; Yang, Y. A multifunctional isolated and non-isolated dual mode converter for renewable energy conversion applications. Energies 2017, 10, 1980. [CrossRef]

5. Voglitsis, D.; Papanikolaou, N.; Kyritsis, A.C. Incorporation of Harmonic Injection in an Interleaved Flyback Inverter for the Implementation of an Active Anti-Islanding Technique. IEEE Trans. Power Electron. 2017, 32, 8526-8543. [CrossRef]

6. Rezaei, M.A.; Kui-Jun, L.; Huang, A.Q. A high-efficiency flyback micro-inverter with a new adaptive snubber for photovoltaic applications. IEEE Trans. Power Electron. 2016, 31, 318-327. [CrossRef]

7. Park, J.; Roh, Y.S.; Moon, Y.J.; Yoo, C. A CCM/DCM dual-mode synchronous rectification controller for a high-efficiency flyback converter. IEEE Trans. Power Electron. 2014, 29, 768-774. [CrossRef]

8. Brockveld, S.L.; Waltrich, G. Boost-flyback converter with interleaved input current and output voltage series connection. IET Power Electron. 2018, 11, 1463-1471. [CrossRef]

9. Cheng, H.L.; Chang, Y.N.; Chang, C.H.; Hsieh, S.Y.; Cheng, C.A. A novel high-power-factor AC/DC LED driver with dual Flyback converters. IEEE J. Emerg. Sel. Top. Power Electron. 2018. [CrossRef]

10. Hasan, R.; Mekhilef, S.; Seyedmahmoudian, M.; Horan, B. Grid-connected isolated PV microinverters: A review. Renew. Sustain. Energy Rev. 2017, 67, 1065-1080. [CrossRef]

11. Getachew, B.W.; Asegid, B.K. Autotransformer fed traction power supply system: analysis, modeling and simulation. Glob. Energy Interconnect. 2018, 1, 187-196.

12. Sher, H.A.; Addoweesh, K.E.; Al Haddad, K. An efficient and cost-effective hybrid MPPT method for a photovoltaic flyback micro-inverter. IEEE Trans. Sustain. Energy 2017, 9, 1137-1141. [CrossRef]

13. Edwin, F.F.; Xiao, W.; Khadkikar, V. Dynamic modeling and control of interleaved flyback module-integrated converter for PV power applications. IEEE Trans. Ind. Electron. 2014, 61, 1377-1388. [CrossRef]

14. Gonzalez, L.G.; Vanegas, P.; Sempertegui, R.; Carranza, O. Peak control current in boundary conduction mode and discontinuous conduction mode for inverter with flyback topology. In Proceedings of the IEEE 2015 IEEE Workshop on Power Electronics and Power Quality Applications (PEPQA), Bogota, Colombia, 2-4 June 2015.

15. Kim, Y.H.; Ji, Y.H.; Kim, J.G.; Jung, Y.C.; Won, C.Y. A new control strategy for improving weighted efficiency in photovoltaic AC module-type interleaved flyback inverters. IEEE Trans. Power Electron. 2013, 28, 2688-2699. [CrossRef]

16. Zhiliang, Z.; Xiao, F.H.; Yan, F.L. An optimal control method for photovoltaic grid-tied-interleaved flyback microinverters to achieve high efficiency in wide load range. IEEE Trans. Power Electron. 2013, 28, 5074-5087.

17. Kamil, M. Grid-Connected Solar Microinverter Reference Design Using a dsPIC Digital Signal Controller; Microchip Application Notes AN1338; Microchip Technology Inc.: Chandler, AZ, USA, 2010.

18. Kamil, M. Grid-Connected Solar Microinverter Reference Design Using a dsPIC Digital Signal Controller; Microchip Application Notes AN1444; Microchip Technology Inc.: Chandler, AZ, USA, 2010.

19. Gao, M.; Chen, M.; Zhang, C.; Qian, Z. Analysis and implementation of an improved flyback inverter for photovoltaic AC module applications. IEEE Trans. Power Electron. 2014, 29, 3428-3444. [CrossRef]

20. Kim, J.W.; Jung, P.M.; Gun, W.M. Analysis and design of a single-switch forward-flyback two-channel LED driver with resonant-blocking capacitor. IEEE Trans. Power Electron. 2016, 31, 2314-2323. [CrossRef] 
21. Zengin, S.; Firat, D.; Mutlu, B. Volt-second-based control method for discontinuous conduction mode flyback micro-inverters to improve total harmonic distortion. IET Power Electron. 2013, 6, 1600-1607. [CrossRef]

22. Sun, J.; Mitchell, D.M.; Greuel, M.F.; Krein, P.T.; Bass, R.M. Averaged modeling of PWM converters operating in discontinuous conduction mode. IEEE Trans. Power Electron. 2001, 16, 482-492.

23. Li, Q.; Yao, K.; Song, J.; Xu, H.; Han, Y. A series diode method of suppressing parasitic oscillation for boost PFC converter operated in discontinuous conduction mode. IEEE Trans. Power Electron. 2018, 33, 407-424. [CrossRef]

24. Delavaripour, H.; Mirzaeian Dehkordi, B.; Adib, E.; Abootorabi Zarchi, H. Dynamic model development and control for multiple-output flyback converters in DCM and CCM. Int. J. Circ. Theory Appl. 2018, 46, 1228-1248. [CrossRef]

25. Mira, M.C.; Zhang, Z.; Knott, A.; Andersen, M.A. Analysis, design, modeling, and control of an interleaved-boost full-bridge three-port converter for hybrid renewable energy systems. IEEE Trans. Power Electron. 2017, 32, 1138-1155. [CrossRef]

26. Chen, M.; Gao, F.; Li, R.; Li, X. A dual-input central capacitor dc/dc converter for distributed photovoltaic architectures. IEEE Trans. Ind. Appl. 2017, 53, 305-318. [CrossRef]

27. Agrawal, A.; Shrivastava, A.; Jana, K.C. Uniform model and analysis of PWM DC-DC converter for discontinuous conduction mode. IETE J. Res. 2017, 1-13. [CrossRef]

28. Kim, H.; Lee, J.S.; Lai, J.S.; Kim, M. Iterative learning controller with multiple phase-lead compensation for dual-mode flyback inverter. IEEE Trans. Power Electron. 2017, 32, 6468-6480. [CrossRef]

29. Wang, H.; Yang, C.; Yan, F.L. A passive-impedance-matching technology to achieve automatic current sharing for a multiphase resonant converter. IEEE Trans. Power Electron. 2017, 32, 9191-9209. [CrossRef]

30. Wang, H.; Chen, Y.; Qiu, Y.; Fang, P.; Zhang, Y.; Wang, L.; Yang, Z.A. Common capacitor multiphase LLC converter with passive current sharing ability. IEEE Trans. Power Electron. 2018, 33, 370-387. [CrossRef]

31. Shi, J.; Liu, T.; Cheng, J.; He, X. Automatic current sharing of an input-parallel output-parallel (IPOP)-connected DC-DC converter system with chain-connected rectifiers. IEEE Trans. Power Electron. 2015, 30, 2997-3016. [CrossRef]

32. He, J.; Yun, W.L. Analysis, design, and implementation of virtual impedance for power electronics interfaced distributed generation. IEEE Trans. Ind. Appl. 2011, 47, 2525-2538. [CrossRef]

33. Sun, Y.; Hou, X.; Yang, J.; Han, H.; Su, M.; Guerrero, J.M. New perspectives on droop control in AC microgrid. IEEE Trans. Ind. Electron. 2017, 64, 5741-5745. [CrossRef]

34. Su, M.; Liu, Z.; Sun, Y.; Han, H.; Hou, X. Stability analysis and stabilization methods of DC microgrid with multiple parallel-connected DC-DC converters loaded by CPLs. IEEE Trans. Smart Grid 2018, 9, 132-142. [CrossRef]

35. Liu, Z.; Su, M.; Sun, Y.; Han, H.; Hou, X.; Guerrero, J.M. Stability analysis of DC microgrids with constant power load under distributed control methods. Automatica 2018, 90, 62-72. [CrossRef]

36. Ye, T.; Dai, N.; Lam, C.S.; Wong, M.C.; Guerrero, J.M. Analysis, Design, and Implementation of a Quasi-proportional-resonant controller for a multifunctional capacitive-coupling grid-connected inverter. IEEE Trans. Ind. Appl. 2016, 52, 4269-4280. [CrossRef]

37. Davoudi, A.; Juri, J.; Tom, D.R. Numerical state-space average-value modeling of PWM DC-DC converters operating in DCM and CCM. IEEE Trans. Power Electron. 2006, 21, 1003-1012. [CrossRef]

38. Sucu, M. Parametric Average Value Modeling of Flyback Converters in CCM and DCM Including Parasitics and Snubbers. Master's Thesis, University of British Columbia, Vancouver, BC, Canada, 2011.

39. Fonkwe, E.; James, K. Current distortion around grid zero-volt crossing and open-loop power factor in flyback AC module with a pseudo-DC link. In Proceedings of the 2015 IEEE International Conference on Smart Grid and Clean Energy Technologies (ICSGCE), Offenburg, Germany, 20-23 October 2015.

40. Kyritsis, A.C.; Tatakis, E.C.; Papanikolaou, N.P. Papanikolaou. Optimum design of the current-source flyback inverter for decentralized grid-connected photovoltaic systems. IEEE Trans. Energy Convers. 2008, 23, 281-293. [CrossRef]

41. Thang, T.V.; Thao, N.M.; Jang, J.H.; Park, J.H. Analysis and design of grid-connected photovoltaic systems with multiple-integrated converters and a pseudo-dc-link inverter. IEEE Trans. Ind. Electron. 2014, 61, 3377-3386. [CrossRef]

42. Padmanaban, S.; Ozsoy, E.; Fedák, V.; Blaabjerg, F. Development of sliding mode controller for a modified boost ćuk converter configuration. Energies 2017, 10, 1513. [CrossRef] 
43. Huang, M.; Liu, Y.; Zhang, N.; Xiong, N.; Liu, A.; Zeng, Z.; Song, H. A services routing based caching scheme for cloud assisted CRNs. IEEE Access. 2018, 6, 15787-15805. [CrossRef]

44. Sencer, B.; Mori, T.; Shamotoc, E. Design and application of a sliding mode controller for accurate motion synchronization of dual servo systems. Control Eng. Pract. 2013, 21, 1519-1530. [CrossRef]

45. Song, D.; Yang, J.; Cai, Z.; Dong, M.; Joo, Y.H. Model predictive control with finite control set for variable-speed wind turbines. Energy 2017, 126, 564-572. [CrossRef]

46. Slotine, J.J.E.; Weiping, L. Applied Nonlinear Control; Prentice Hall: Englewood Cliffs, NJ, USA, 1991; Volume 199. article distributed under the terms and conditions of the Creative Commons Attribution (CC BY) license (http:/ / creativecommons.org/licenses/by/4.0/). 